\title{
A Multiplexed Fluorescent Calcium and NFAT Reporter Gene Assay to Identify GPCR Agonists
}

\author{
Heeral Sheth ${ }^{1, \#}$, Colleen Gorey ${ }^{2, \#}$, Nicole Roush ${ }^{3}$, Shelly Smallman ${ }^{3}$, Elizabeth Collantes ${ }^{3}$, Maxine \\ Santoro $^{3}$, Barbara Olson ${ }^{3}$, Laura Fitzgerald ${ }^{3}$, Paul H. Lee ${ }^{4}$ and Xiqiang John Shen ${ }^{3, *}$ \\ ${ }^{1}$ Lawrence Livermore National Laboratory, Livermore, CA 94550, USA \\ ${ }^{2}$ Department of Chemical and Environmental Engineering, University of Toledo, Toledo $\mathrm{OH} 43606$, USA \\ ${ }^{3}$ Pfizer Global Research and Development, Groton Laboratories, Groton, CT 06340, USA \\ ${ }^{4}$ Amgen, Inc., Lead Discovery, Thousand Oaks, CA 91320, USA
}

\begin{abstract}
Intracellular calcium response and resulting calcium signaling to an agonist-GPCR interaction are important for the measurement of compound activity in the GPCR drug development. The increase in cytosol calcium concentration can be measured by the fluorescent calcium indicator dye such as Fluo-4 in a quick assay (in 3-5 minutes) using the fluorescence imaging plate reader. The calcium signaling through the transcription factors such as NFAT that induces gene expression can be measured by the reporter gene assay that links to the expression of reporter enzyme such as the betalactamase that requires 5-hour incubation. We have evaluated a multiplexed assay that sequentially measures the calcium response to a GPCR agonist in a rapid fluorescent calcium dye assay, followed by a NFAT beta-lactamase assay, and compared them in the single assay format. We found that the agonist activity determined in the multiplexed assay were comparable with these determined in the single assay format and the $\mathrm{Z}$ ' factors were all $>0.5$. Five active compounds were identified that were active in both calcium dye assay and beta-lactamase assay. Therefore, our results demonstrated the utility of this multiplexed calcium assay for screening of GPCR compounds that can cross validate the primary hits and help to eliminate the false positive compounds.
\end{abstract}

Keywords: FLIPR assay, fluorescent calcium assay, beta-lactamase reporter gene assay, GPCR, high throughput screening, multiplex assay.

\section{INTRODUCTION}

G-protein-coupled receptors (GPCRs) are a large family of trans-membrane receptors that bind to extracellular agonists to activate intracellular signal transduction pathways including calcium, cAMP, ERK-phosphorylation and betaarrestin $[1,2]$. The location of these receptors on the cell membrane and the extracellular interaction site of ligands with receptors allow easily accessing of therapeutic compounds that modify the biological functions of these receptors. GPCRs are traditional targets of drug therapies and there are more than $30 \%$ of the currently available medications that are targeting GPCRs $[3,4]$.

Intracellular calcium release stimulated by a GPCR agonist initiates an important signaling pathway that triggers a variety of cellular functions including cell secretion, muscle contraction and neurotransmitter release. Calcium mobilization also activates downstream calcium-dependent tran-

*Address correspondence to this author at the Therapeutics for Rare and Neglected Diseases (TRND), National Center for Advancing Translational Sciences (NCATS), National Institutes of Health (NIH), 9800 Medical Center Drive, Rockville, MD 20850, USA; Tel: +1-301-827-2512;

Fax: +1-301-827-2534; E-mail: john.shen@nih.gov

"Both authors contribute equally

2213-9885/13 scription factors, such as nuclear factor of activated T-cells (NFAT) that regulates gene expression [1]. Because the calcium mobilization occurs early in the signaling pathway, it is a measurement point for assessing the quick response of compounds. The measurement of NFAT response on a GPCR agonist usually involves gene transcription that reports the late response of GPCR activation. Thus, a combination of an early response with a late response for a compound screening assay may help to identify additional information and property of the compounds acting on the GPCR.

Cell based assays with the high throughput screening (HTS) technology have become increasingly popular in drug discovery and development [5-7]. The new challenge in cell based assays includes generation of an appropriate cell model, adaptation to robotic screening platform, and elimination of false positive compounds. Currently, the main HTS assay for measurement of cytosol calcium concentration is based on the fluorescent calcium binding dyes such as Fluo4 (excitation wavelength of $488 \mathrm{~nm}$, emission wavelength of $520 \mathrm{~nm}$ ). Other calcium indicator dyes are also available including Fura-2, Indo-1, Calcium Green, and Calcium Orange though they are not appropriate for HTS. The NFATreporter gene assay has also been used for the measurement of intracellular calcium response to a GPCR agonist such as the beta-lactamase assay with the GeneBLAzer ${ }^{\circledR}$ technology 
A.
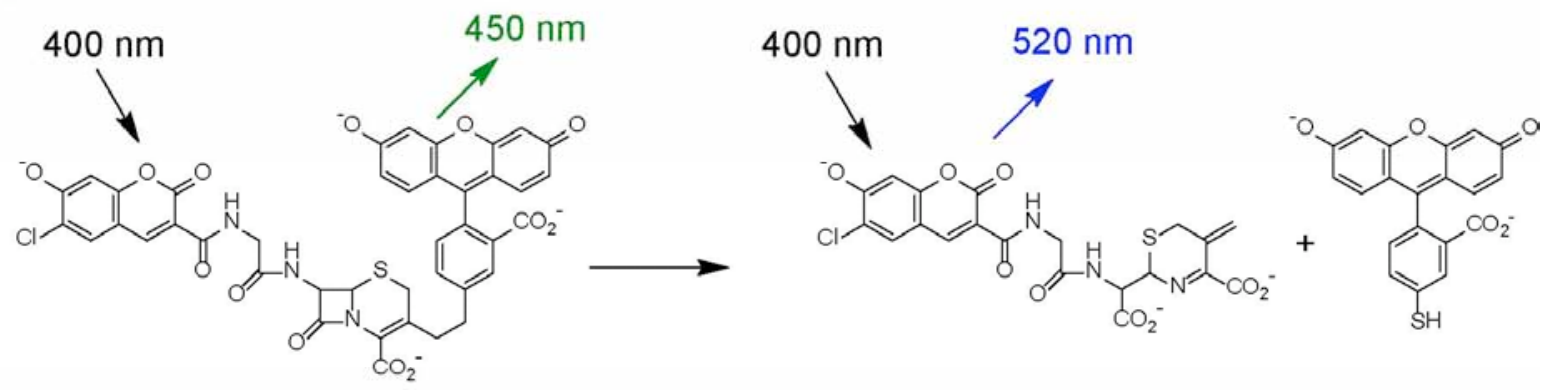

CCF2 (substrate)

Product-1

product-2

B.

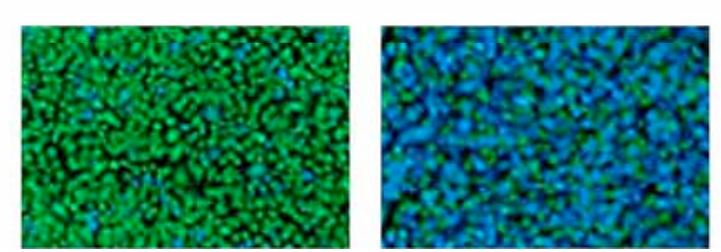

Fig. (1). Schematic diagram of coumarin cephalosporin fluorescein (CCF) cleaved by $\beta$-lactamase. After the substrate CCF-acetoxymethyl ester (AM) enters the cell, it is converted into CCF by endogenous esterases, thereby trapping it inside the cell. Excitation of CCF at $409 \mathrm{~nm}$ leads to FRET (A) from the coumarin moiety to the fluorescein derivative that produces green fluorescence detectable at $520 \mathrm{~nm}$ (green cells, B). In the presence of $\beta$-lactamase, the CCF substrate is cleaved to form two fluorophores that disrupts FRET. Excitation at $409 \mathrm{~nm}$ now produces a fluorescence detectable at $447 \mathrm{~nm}$ (blue cells, B) [8, 9].

$[8,9]$. In this assay, increase in intracellular calcium by a GPCR agonist stimulates the production of beta-lactamase that turns the substrate from green color to blue color (Fig. 1). Here we report a multiplexing assay approach for GPCR compound screens that sequentially measures an intracellular calcium response detected by the calcium indicator Fluo- 4 and the activity of beta-lactamase reporter in response to GPCR agonists or compounds. This multiplex assay enables measurements of GPCR-Ca signaling pathway at two different levels, which has not only saved time and cost for HTS but will also help to eliminate false positive hits.

\section{MATERIALS AND METHODS}

\section{Materials}

The CHO Go15NFATbla-MT ${ }_{1}$ cell line stably expressing the $\mathrm{MT}_{1}$ (melatonin receptor 1) and $\beta$-lactamase under control of the NFAT response element was obtained from Donald Vanleeuwen (Pfizer Global R\&D). The Fluo-4 NW (NW: no wash) Calcium Assay Kit was obtained from Molecular Probes/Life Technologies. The GeneBLAzer® assay kit was obtained from Invitrogen (Carlsbad, CA). The compounds were ordered from the Pfizer compound library. All cell culture components were obtained from Invitrogen (Carlsbad, CA), with the exception of Puromycin and Probenecid in $\mathrm{NaOH}$ solution, which were obtained from Sigma-Aldrich (St. Louis, MO). The assay buffer components used for the multiplexing experiment were Dulbecco's Modified Eagle Medium (DMEM, Invitrogen, \#31053-028), dialyzed Fetal Bovine Serum (dFBS, Invitrogen \#26400036), Non-Essential Amino Acids (NEAA, Invitrogen, \#11140-050), HEPES (Invitrogen, \#15630-080), Lglutamine (Invitrogen, \#35050-061), Na-Pyruvate (Invitrogen, \#11360-070), and Probenecid in $\mathrm{NaOH}$ (Sigma Aldrich, P8761). Costar® (Cambridge, MA) 384-well plates with clear bottoms (\#3712) were used for seeding and assaying the $\mathrm{CHO}_{-} \mathrm{MT}_{1}$ cells.

\section{Cell Culture}

$\mathrm{MT}_{1}$ NFAT-bla Frozen CHO cells were frozen at $3 \times 10^{7}$ cells $/ \mathrm{ml}$ in DMEM supplemented with $10 \% \mathrm{dFBS}, 0.1 \mathrm{mM}$ nonessential amino acids, $25 \mathrm{mM}$ HEPES, Zeocin, Blasticidin, and Puromycin. The cells were grown in T-150 flasks (BD Biosciences, \#15705-074) at $37^{\circ} \mathrm{C} / 5 \% \mathrm{CO}_{2}$, and frozen into vials. One vial was sufficient for seeding 5 plates at 12,000 cells per well.

\section{Fluo-4 Calcium Dye Assay}

The Fluo-4 NW dye was prepared according to the manufacturer's directions, with the exception of the buffer medium (included in the pack) being replaced by the assay medium containing phenol-red free DMEM, 0.1\% dFBS, 0.1mM NEAA, 25mM HEPES, $3.97 \mathrm{mM}$ L-Glutamine, $1 \mathrm{mM}$ NaPyruvate, and $2.5 \mathrm{mM}$ Probenecid in $\mathrm{NaOH}$. The cells were plated overnight in a 384-well plate in phenol-red DMEM, 5\% dFBS, 0.1mM NEAA, and 25mM HEPES, at 12,000 cells/well in $40 \mu \mathrm{l}$ of solution. Cells were incubated overnight at $37^{\circ} \mathrm{C} / 5 \% \mathrm{CO}_{2}$ to allow the cells to adhere to the plate bottom. The following day, the media was removed from the wells, and replaced with $30 \mu \mathrm{l}$ of Fluo-4 NW dye solution. Cells were incubated at $37^{\circ} \mathrm{C} / 5 \% \mathrm{CO}_{2}$ for 1 hour, and assayed immediately. The assay medium added to the Fluo-4 NW dye in the stand-alone protocol contains $90 \%$ Hank's Balanced Salt Solution, 25mM HEPES, and 2.5mM Probenecid in $\mathrm{NaOH}$ solution.

\section{Compound Plate Preparation}

A set of 32 96-well master stock plates were prepared at a high concentration of $4 \mathrm{mM}$, with a 10 point curve at a $1: 4$ dilution ratio. Two columns are high control of 2- 
iodomelatonin at $1 \mathrm{mM}$, and two columns are low control of $100 \%$ DMSO. Each master plate was stamped into four compound assaying plates at $0.5 \mu l$ per well, and diluted with $50 \mu \mathrm{l}$ of the same assay medium used to dilute the Fluo-4 NW dye. The final high concentration of testing compound and final high control were $4 \mu \mathrm{M}$ and $1 \mu \mathrm{M}$, respectively. Final DMSO concentration was $0.25 \%$.

\section{Multiplexed Fluo-4 Calcium and NFAT-Beta-Lactamas Reporter Gene Assay}

The FLIPR liquid handling device from Molecular Devices (Sunnyvale, CA) had a 384 well-head, and was used for compound addition and testing with Fluo-4 NW dye for the FLIPR multiplexed and stand-alone screens. During compound testing, cells were stimulated with $10 \mathrm{uL}$ of the compound, and control wells were stimulated with 2iodomelatonin. Each 384-well cell plate contained a control column of wells without cells creating a background subtraction column. Data was obtained for $\sim 180$ seconds after compound addition, and plotted as the difference between the maximum and minimum stimulation values ( $\Delta$ Max-Min). Tips were changed between each cell plate. For the $\beta$ lactamase stand-alone screen, compound was added to the cell plate using Molecular Devices FX robotic liquid handler. Following compound addition, the plates were incubated at $37{ }^{\circ} \mathrm{C} / 5 \% \mathrm{CO}_{2}$ for 5 hours.

Cells were then loaded with GeneBLAzer ${ }^{\circledR}$ CCF4-AM dye. For the $\beta$-lactamase multiplexed and stand-alone screens, a loading solution was prepared consisting of $12 \mu \mathrm{l}$ of solution A, $60 \mu$ l of Solution B, $925 \mu$ l of Solution C, and $75 \mu l$ of Probenecid in Phosphate buffer. Then, $10 \mu \mathrm{l}$ of the CCF4-AM dye solution was added to each well of the screening plates. The plates were incubated at $37{ }^{\circ} \mathrm{C} / 5 \% \mathrm{CO}_{2}$ for 2 hours at room temperature (in the dark to prevent degradation by light) prior to reading fluorescence on the Analyst AD from Applied Biosystems (Foster City, CA) at an excitation filter of $425 \mathrm{~nm}$ and emission filters of $460 / 40 \mathrm{~nm}$ and $530 / 30 \mathrm{~nm}$. Data are presented in blue/green ratio of each well divided by the average of the blue/green ratio of the un-stimulated control wells.

\section{Data Analysis}

Data for the Fluo-4 NW screen were analyzed in SpotFire® (TIBCO Software Inc., Palo Alto, CA), a valuable tool for removing outliers and presenting $\mathrm{EC}_{50}$ values from the linear regression model of each agonist. Microsoft Excel (Redmond, WA) was used to compile all data from the multiplexed and stand-alone screens.

$$
\% \text { Activity }=\frac{\text { ExperimentalValue }- \text { LowControl }}{\text { HighControl }- \text { LowControl }}
$$

The $\%$ activity was calculated for the Fluo-4 NW and $\beta$ lactamase data sets. Two sets are considered: $\%$ activity above $30 \%$, and above $50 \%$. The multiplexed and stand-alone results were compared to analyze assay 'hit' consistency.

\section{RESULTS}

Multiplexing the FLIPR Calcium Assay with NFAT Beta-Lactamase Reporter Gene Assay

The FLIPR calcium assay with a Fluo-4 no wash dye kit in the single assay format used the standard assay buffer consisting of $90 \%$ HBSS with $25 \mathrm{mM}$ HEPES, and $2.5 \mathrm{mM}$ Probenecid. However, this assay buffer was not adequate for the multiplexed assay because the cells did not survive the $5 \mathrm{hr}$ incubation for the subsequent NFAT beta-lactamase assay followed the FLIPR calcium assay. The growth media and overnight assay media for the MT1 CHO cells contained DMEM and dFBS. We found that the optimized assay buffer for the multiplexed assay consisted of DMEM without phenol-red, high glucose, Na-Pyruvate and L-glutamine and $0.1 \%$ dFBS with $2.5 \mathrm{mM}$ Probenecid. The cells in this assay buffer produced optimal signal in the FLIPR calcium assay with the Fluo-4 no wash dye (Fig. 2). The slight reduction in the beta-lactamase signal in this assay buffer may be a result from the incubation with Probenecid for 5 hours. However, the $\mathrm{EC}_{50}$ values of MT1 agonist remained same in the $\beta$ lactamase assay determined in the multiplexed assay format compared with that in the single assay format.

The use of frozen cells enables preparing large amount of cells in advance and pools all the cells into the same batch, which: simplifies the HTS process, minimizes the variation due to cell passage numbers, and differences in day-to-day cell culture [10]. The direct use of resuspended frozen $\mathrm{MT}_{1}$ cells were also compared with the fresh cells for both FLIPR calcium assay and NFAT beta-lactamase assay in the single assay and multiplexed assay formatted. We found that the assay windows (signal-to-basal ratio) and EC50 values of the MT1 agonist were similar in the assays with frozen cells compared with the fresh cells. The results demonstrated the effectiveness of using frozen cells for compound screening (Fig. 3).

\section{Assay Validation}

Both FLIPR calcium assays with the Fluo-4 dye and beta-lactamase assay using the $\mathrm{MT}_{1} \mathrm{CHO}$ cells were carried out in the single assay format and multiplexed assay format to compare the $\mathrm{EC}_{50}$ values of agonist and assay performance. As illustrated in the step-by-step assay procedure for the multiplexed assay (Fig. 4), cells in the assay plates, after one day culture, were incubated with Fluo-4 dye for one hour followed by the measurement of intracellular calcium response to the MT1 agonist in the standard FLIPR assay. After an additional $5 \mathrm{hr}$ incubation with the MT1 agonist for the induction of the beta-lactamase reporter gene, the betalactamase substrate was added to the assay plates and followed by an additional $2 \mathrm{hr}$ incubation. The beta-lactamase activity was then measured by detecting emissions at 465 and $520 \mathrm{~nm}$ from excitation at $409 \mathrm{~nm}$. Thus, both assays were measured sequentially from the same assay plate.

\section{Primary Screening of a Compound Library}

The compound screens were performed in the multiplexed assay format in comparison with these in the single assay format. We found that all Z' factor values were greater than 0.5 in the screening test determined in the both assay in the single or multiplexed assay formats (Fig. 5). The assay performance was robust in all the assay formats. The $\mathrm{EC}_{50}$ values and \% activities for each screening format were comparable. The Fluo-4 multiplex and stand-alone formats had corresponding maximum fluorescence outputs; however, the blue/green ratio of the $\beta$-lactamase multiplexed format was slightly lower than the stand-alone protocol. This may be due to the low dFBS concentration in the assay buffer, or the addition of Probenecid (needed for the FLIPR calcium assay) 


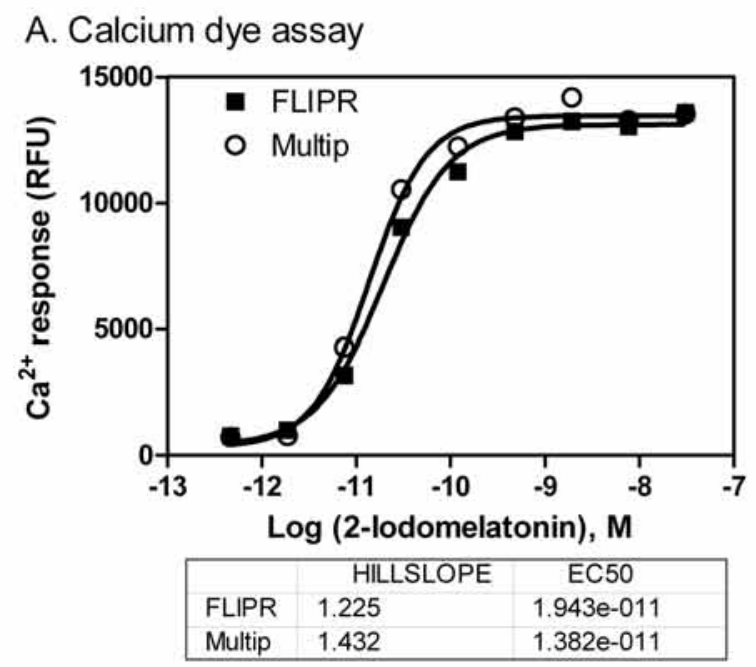

B. NFAT beta-lactamase assay

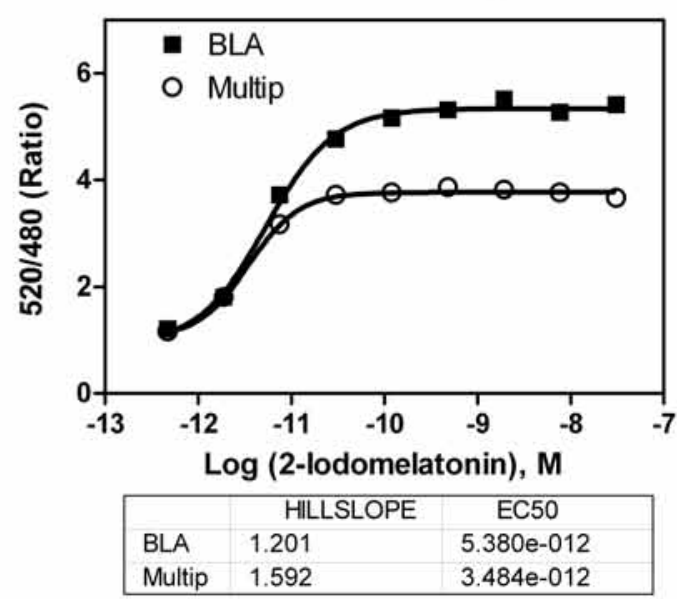

Fig. (2). Comparison of concentration responses of 2-iodomelatonin (a MT1 melatonin receptor agonist) determined in the single assay to these in the multiplexed assay. (A) $\mathrm{EC}_{50}$ values of 2-iodomelatonin were $19.4 \mathrm{nM}$ and $13.8 \mathrm{nM}$ measured in the FLIPR calcium assay in the single assay format (FLIPR) and multiplexed assay format (Multip), respectively. (B) $\mathrm{EC}_{50}$ values of 2-iodomelatonin were $5.38 \mathrm{pM}$ and 3.48 pM determined in the NFAT beta-lactamase reporter gene assay in the single assay format (BLA) and multiplexed assay format (Multip), respectively.
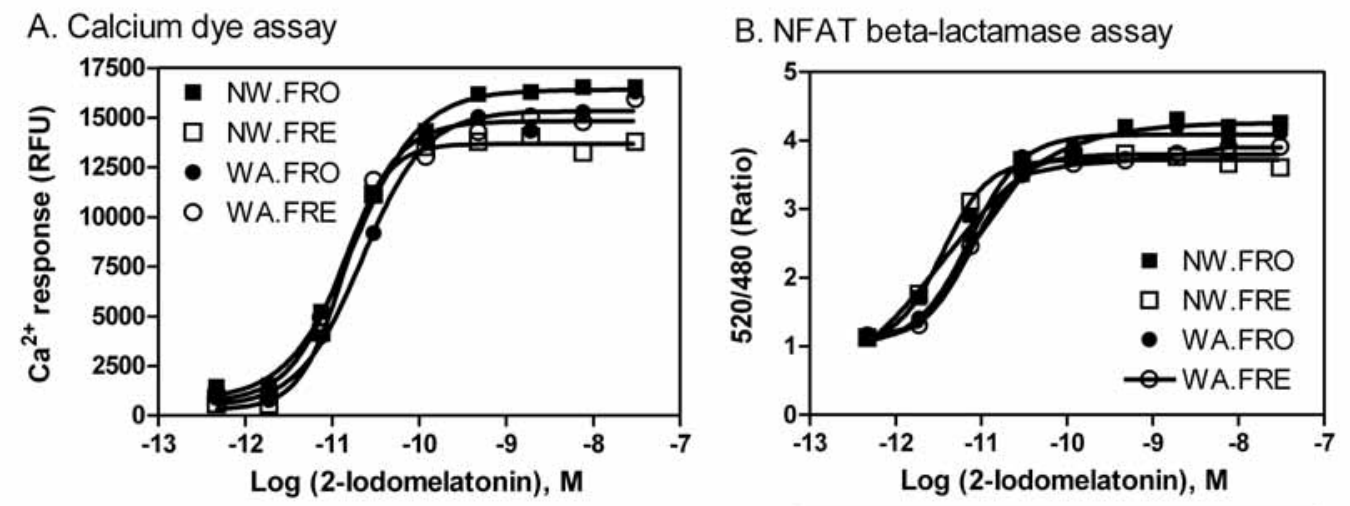

\begin{tabular}{|l|l|c|}
\hline & HILLSLOPE & EC50 \\
\hline NW.FRO & 1.117 & $1.771 \mathrm{e}-011$ \\
\hline NW.FRE & 1.734 & $1.312 \mathrm{e}-011$ \\
\hline WA.FRO & 1.189 & $2.204 \mathrm{e}-011$ \\
\hline WA.FRE & 1.368 & $1.377 \mathrm{e}-011$ \\
\hline
\end{tabular}

\begin{tabular}{|l|l|l|}
\hline & \multicolumn{1}{|c|}{ HILLSLOPE } & EC50 \\
\hline NW.FRO & 0.6798 & $3.601 \mathrm{e}-012$ \\
\hline NW.FRE & 1.646 & $3.567 \mathrm{e}-012$ \\
\hline WA.FRO & 1.415 & $7.370 \mathrm{e}-012$ \\
\hline WA.FRE & 1.542 & $7.739 \mathrm{e}-012$ \\
\hline
\end{tabular}

Fig. (3). Comparison of activities of 2-iodomelatonin determined in the multiplexed assay for the fresh-cells vs. frozen cells and wash vs. nowash conditions. (A) The $\mathrm{EC}_{50}$ values in the FLIPR calcium assay were 17.7, 13.1, 22.0, and 13.8 pM for the frozen cells (NW-FRO) and fresh cells (NW-FRE) in the no-wash assay and the frozen cells (WA-FRO) and fresh cells (WA-FRE) in the cell wash assay, respectively. (B) The $\mathrm{EC}_{50}$ values in the NFAT-beta-lactamase reporter gene assay were 3.60, 3.56, 7.37 and 7.74 pM for the frozen cells (NW-FRO) and fresh cells (NW-FRE) in the no-wash assay and the frozen cells (WA-FRO) and fresh cells (WA-FRE) in the cell wash assay, respectively.

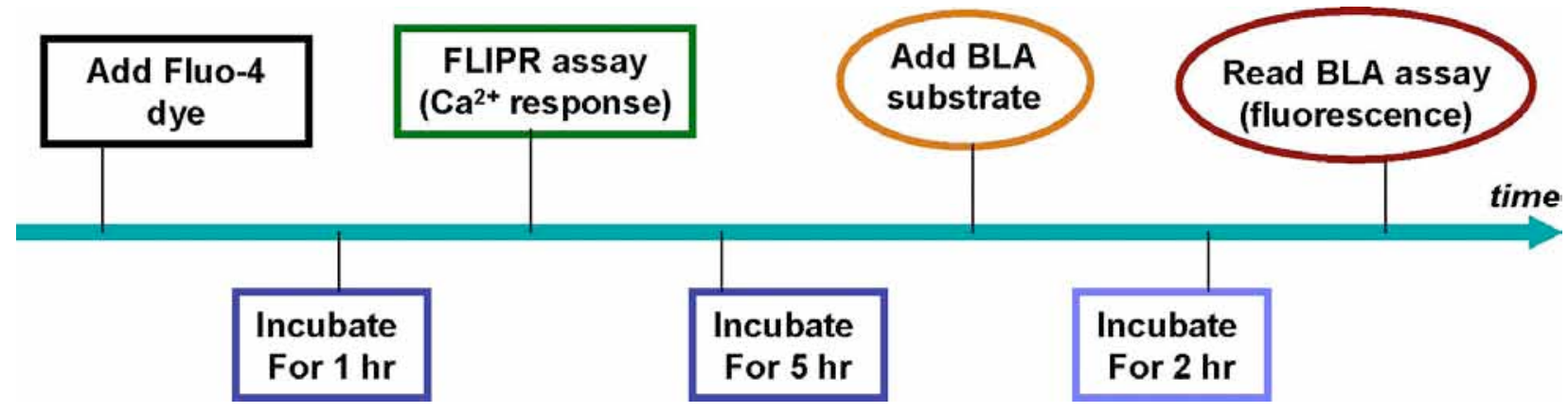

Fig. (4). A step by step illustration of assay procedure for the multiplexed FLIPR calcium and NFAT beta-lactamase assay. 
A. BLA in single assay

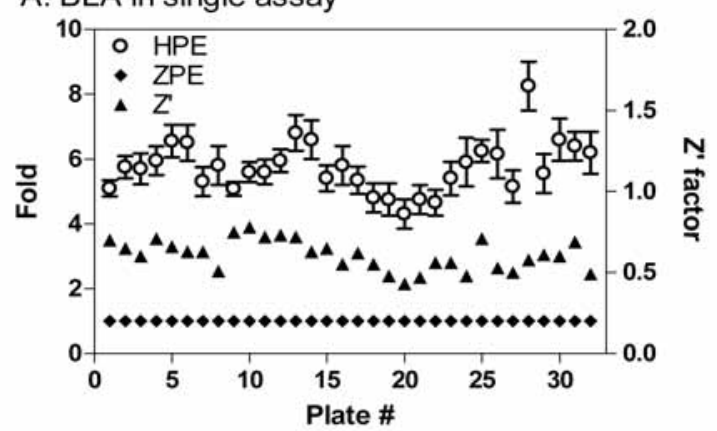

C. Calcium in single assay

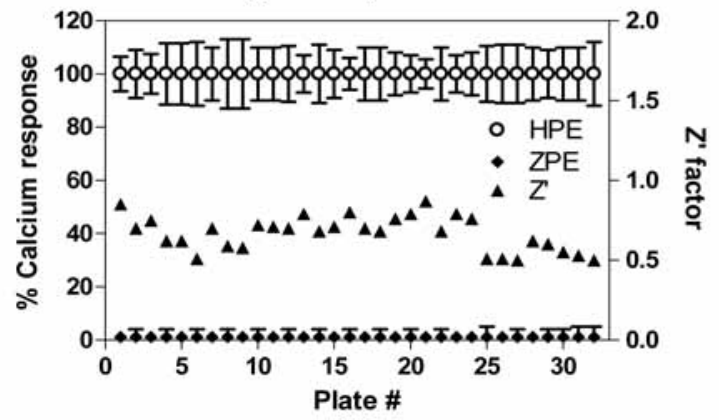

B. BLA in multiplexed assay

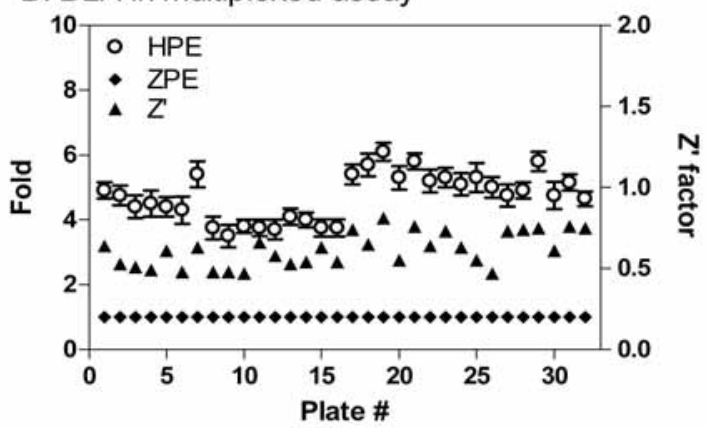

D. Calcium in multiple assay

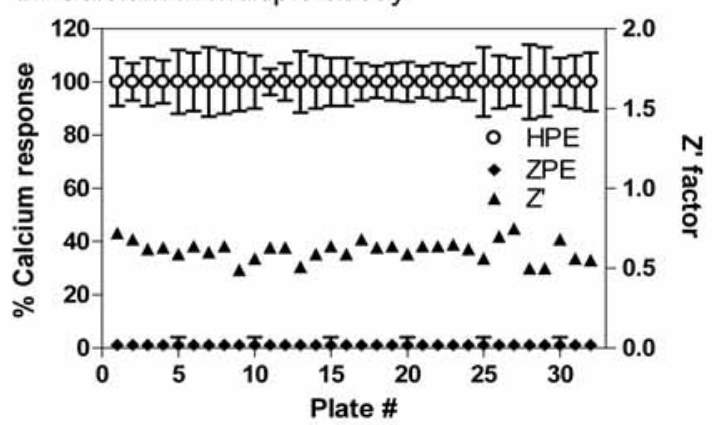

Fig. (5). HTS performance of the multiplexed assay. HPE $(\diamond)$, the positive control wells in each plate were averaged and normalized to $100 \%$ effect in the four assay formats with error bars indicating the standard deviation of high control for each plate. ZPE ( $\mathbf{m})$, the negative control wells were normalized to $0 \%$ effect. Z' Factor values $(\boldsymbol{\Delta})$ were calculated for the thirty-two compound plates tested. All Z' Factor values were greater than 0.5, indicating the robust results from this screen. (A) Results obtained from the NFAT beta-lactamase assay in the single assay format. (B) Results determined from the NFAT beta-lactamase assay in the multiplexed assay format. (C) Results obtained from the FLIPR calcium assay in the single assay format. (D) Results determined from the FLIPR calcium assay in the multiplexed assay.

for $5 \mathrm{hr}$ incubation in the beta-lactamase assay. However, the $\mathrm{EC}_{50}$ values of the compounds were similar in the multiplexed assay compared with these in the single assay format of NFAT beta-lactamase assay (Fig. 6), indicating the results were comparable in both assays.

A total of 253 compounds were selected as the primary hits and the hit rate of $\sim 3 \%$ at a cut-off of $>30 \%$ activity or $\sim 1.7 \%$ at $>50 \%$ activity. Of these hits, 16 compounds were active in all four assay formats ( $>30 \%$ activity) including two in the multiplexed assay and two in the single assay format. For the beta-lactamase assay, there was a $70 \%$ correlation of these hits between the multiplexed assay format and single assay format, while an $85 \%$ correlation of the hits was observed for the FLIPR calcium assay in both assay formats. On the other hand, the multiplexed assay format showed a $73 \%$ hit rate correlation between the beta-lactamase assay and the FLIPR calcium assay (Tables 1, 2, and $\mathbf{3}$ ).

The $\mathrm{EC}_{50}$ values for each of the 16 hits that were active across all four assay formats are shown in Table 4. Five compounds of interest to the $\mathrm{MT}_{1}$ project were also potent hits in all four assay formats (Fig. 6) that were promising as potential agonists of the $\mathrm{MT}_{1}$ receptor.

\section{DISCUSSION}

The fluorescent calcium dye assay measures the quick calcium response to the binding of an agonist to a GPCR, while the NFAT beta-lactamase reporter gene assay meas- ures the calcium signaling from GPCR activation then transactivation of the NFAT reporter gene, beta-lactamase. Thus, the calcium dye assay only shows the early events of GPCR activation including agonist-GPCR binding, activation of $\mathrm{Gq}$ protein and PLC that release second messengers IP3 and DAG. The calcium is then released by the activation of IP3 channels in the intracellular storage site ER. On the other hand, a more complete intracellular calcium signaling pathway is needed for the activation of beta-lactamase transcription by the NFAT reporter gene. Once the cytosol calcium is increased by an agonist-GPCR interaction, calcium ions bind to calmodulin, a calcium sensor protein, which activates calcineurin, a serine/threonine phosphatase and rapidly dephosphorylates NFAT proteins. This allows NFAT enters nucleus where it binds to specific promoters and initiates gene transcription. The disadvantage of NFAT beta-lactamase assay is that it may produce a large amount of false positive hits in compound screens since so many other proteins and factors are involved in its signaling. However, a desired true GPCR activator should activate both of these mechanisms. Therefore, multiplexing the calcium dye assay with the NFAT beta-lactamase reporter gene assay enables a measurement of compound activities in two assays from the same cells. It also greatly saves the screening cost and time.

Since the calcium dye assay only takes a short time, including a 1 hour dye incubation and 3 to 5 minutes for agonist response recording, a simple physiological salt buffer is usually used for the experiment. The NFAT beta-lactamase 
A. Compound-249

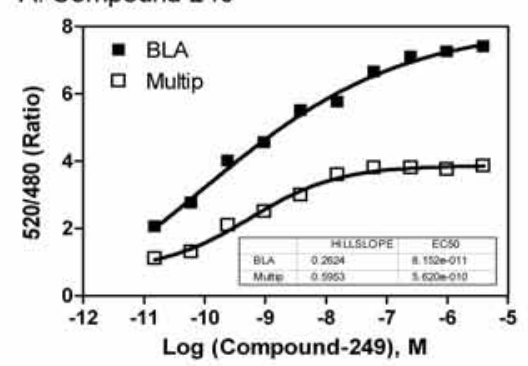

D. Compound-252

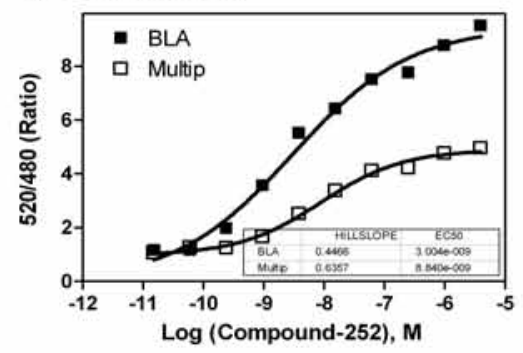

B. Compound-250

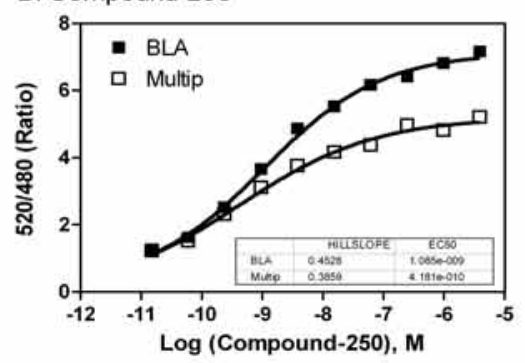

E. Compound-253

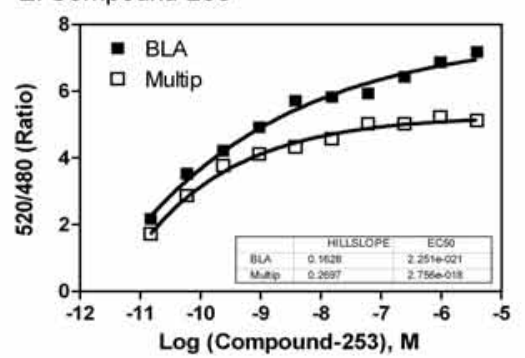

C. Compound-251

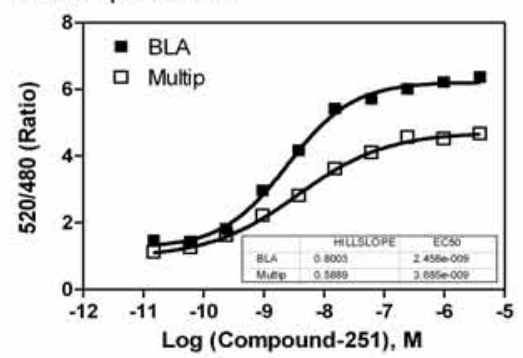

Fig. (6). Concentration responses of five representative active compounds identified from the compound library screen with this multiplexed assay. (A) The $\mathrm{EC}_{50}$ values of Compound \#249 in the NFAT beta-lactamase assay were 0.08 and $0.56 \mathrm{nM}$ in the single assay format and multiplexed assay format, respectively. (B) The $\mathrm{EC}_{50}$ values of Compound \#250 in the NFAT beta-lactamase assay were 1.08 and $0.42 \mathrm{nM}$ the single assay format and multiplexed assay format, respectively. (C) The $\mathrm{EC}_{50}$ values of Compound \#251 in the NFAT beta-lactamase assay were 2.46 and $3.69 \mathrm{nM}$ in the single assay format and multiplexed assay format, respectively. (D) The $\mathrm{EC}_{50}$ values of Compound \#252 in the NFAT betalactamase assay were 3.00 and $8.84 \mathrm{nM}$ in the single assay format and multiplexed assay format, respectively. (E) The EC 50 values of Compound \#253 in the NFAT beta-lactamase assay were 2.25 and $2.76 \mathrm{nM}$ in the single assay format and multiplexed assay format, respectively.

Table 1. Hit Correlation for all Four Type of Assays

\begin{tabular}{|c|c|c|c|c|c|}
\hline \multirow[b]{2}{*}{ Hit ratio } & \multicolumn{2}{|c|}{253 Compounds (All) } & \multirow[b]{2}{*}{ Hit ratio } & \multicolumn{2}{|c|}{52 Compounds (hits only) } \\
\hline & Hit (30\%) & Hit $(50 \%)$ & & Hit (30\%) & Hit $(50 \%)$ \\
\hline $4 / 4$ & 6.37 & 4.78 & $4 / 4$ & 30.7 & 23.1 \\
\hline $3 / 4$ & 2.39 & 3.19 & $3 / 4$ & 11.5 & 15.3 \\
\hline $2 / 4$ & 3.98 & 2.39 & $2 / 4$ & 19.2 & 11.5 \\
\hline $1 / 4$ & 7.97 & 5.98 & $1 / 4$ & 38.4 & 28.8 \\
\hline $0 / 4$ & 79.3 & 83.7 & $0 / 4$ & 0 & 21.1 \\
\hline Summary & 100 & 100 & Summary & 100 & 100 \\
\hline
\end{tabular}

Table 2. Assay Pairwise Correlation for Hits Above $30 \%$ Effect

\begin{tabular}{|c|c|c|c|c|c|}
\hline & & 1 & 2 & 3 & 4 \\
\hline 1 & BLA & 26 & 18 & 21 & 17 \\
\hline 2 & M_BLA & 18 & 26 & 21 & 19 \\
\hline 3 & FLIPR & 21 & 21 & 37 & 28 \\
\hline
\end{tabular}

Table 3. Assay Three and Four-Way Correlation for Hits Above 30\% Effect

\begin{tabular}{|c|c|c|c|c|c|c|c|c|c|c|c|c|c|c|}
\hline \multicolumn{3}{|c|}{ Combination A } & \multicolumn{3}{|c|}{ Combination B } & \multicolumn{3}{|c|}{ Combination $\mathrm{C}$} & \multicolumn{3}{|c|}{ Combination D } & \multicolumn{3}{|c|}{ Combination $\mathbf{E}$} \\
\hline 1 & BLA & 26 & 2 & M_BLA & 26 & 1 & BLA & 26 & 1 & BLA & 26 & 1 & BLA & 26 \\
\hline 2 & M_BLA & 26 & 3 & FLIPR & 26 & 2 & M_BLA & 26 & 3 & FLIPR & 37 & 2 & M_BLA & 26 \\
\hline
\end{tabular}


Table 3. contd....

\begin{tabular}{|c|c|c|c|c|c|c|c|c|c|c|c|c|c|c|}
\hline \multicolumn{3}{|c|}{ Combination A } & \multicolumn{3}{|c|}{ Combination B } & \multicolumn{3}{|c|}{ Combination $\mathrm{C}$} & \multicolumn{3}{|c|}{ Combination D } & \multicolumn{3}{|c|}{ Combination $\mathbf{E}$} \\
\hline 3 & FLIPR & 37 & 4 & M_FLIPR & 33 & 4 & M_FLIPR & 33 & 4 & M_FLIPR & 33 & 3 & FLIPR & 37 \\
\hline & & & & & & & & & & & & 4 & M_FLIPR & 33 \\
\hline & Match & 18 & & Match & 19 & & Match & 16 & & Match & 17 & & Match & 16 \\
\hline
\end{tabular}

Table 4. $\mathbf{E C}_{50}$ Values for the 16 Hits Across all Four Assay Formats

\begin{tabular}{|c|c|c|c|c|c|c|c|c|}
\hline \multirow[t]{2}{*}{ Compound \# } & \multicolumn{2}{|c|}{ BLA } & \multicolumn{2}{|c|}{ M_BLA } & \multicolumn{2}{|c|}{ FLIPR } & \multicolumn{2}{|c|}{ M_FLIPR } \\
\hline & $\mathbf{E C}_{50}$ & \%Activity & $\mathbf{E C}_{50}$ & \%Activity & $\mathbf{E C}_{50}$ & \%Activity & $\mathbf{E C}_{50}$ & \%Activity \\
\hline 40 & 18.9 & 113.9 & 31.9 & 87.7 & 4.54 & 75.6 & 5.20 & 83.3 \\
\hline 144 & 248.9 & 84.2 & 807 & 36.8 & 8.19 & 103.5 & 15.6 & 85.2 \\
\hline 148 & 0.097 & 100.4 & 0.371 & 103.8 & 0.046 & 113.9 & 0.106 & 89.6 \\
\hline 202 & 38.5 & 96.6 & 50.7 & 65.1 & 1.36 & 91.1 & 0.575 & 82.7 \\
\hline 205 & 69.8 & 51.7 & 109 & 37.9 & 31.4 & 73.8 & 6.87 & 94.5 \\
\hline 234 & 772.6 & 59.4 & 1900 & 46.0 & 204.9 & 66.8 & 205 & 66.5 \\
\hline 237 & 378.0 & 74.0 & 256 & 54.1 & 18.7 & 105.3 & 18.8 & 104.4 \\
\hline 240 & 2.95 & 139.3 & 7.83 & 102.4 & 0.333 & 97.7 & 0.329 & 96.9 \\
\hline 241 & 850.2 & 59.2 & 1100 & 30.4 & 355.7 & 52.1 & 356 & 51.9 \\
\hline 243 & 871.4 & 65.9 & 679 & 39.1 & 364.6 & 74.5 & 365 & 73.8 \\
\hline 248 & 1.10 & 116.3 & 8.48 & 74.9 & 0.082 & 105.2 & 0.082 & 104.0 \\
\hline 249 & 0.599 & 119.9 & 0.671 & 77.1 & 0.065 & 76.8 & 0.065 & 78.0 \\
\hline 250 & 0.810 & 111.0 & 0.764 & 102.6 & 0.009 & 96.2 & 0.009 & 97.7 \\
\hline 251 & 0.955 & 97.5 & 0.350 & 98.0 & 0.037 & 105.9 & 0.037 & 107.5 \\
\hline 252 & 0.950 & 147.2 & 0.433 & 104.5 & 0.056 & 99.1 & 0.056 & 95.6 \\
\hline 253 & 0.020 & 91.2 & 0.093 & 115.7 & 0.040 & 115.2 & 0.040 & 116.9 \\
\hline
\end{tabular}

assay requires long agonist incubation time (usually 5 hours) for the expression of reporter gene and thus cell culture medium over buffer is preferred. Thus, we have optimized the assay buffer for this multiplexed assay that consists of $0.1 \%$ dFBS, high glucose DMEM without phenol-red and with added Na-Pyruvate and L-glutamine, and $2.5 \mathrm{mM}$ Probenecid. The addition of Probenecid is needed to prevent dye leaking out of cells through membrane transporters. The main advantages of using a single plate for two calcium assays for compound screens include savings in screening cost and time and more comparable results from two assays because the compound activities were determined from the same cells for the calcium dye and NFAT beta-lactamase reporter gene assays.

Cell culture to produce a large amount of cells for compound screens in a HTS format is a challenge because the day-to-day variation of yields and different cell passage numbers can cause increased variation in the screening results. Application of frozen cells has been used to minimize such a variation among the compound screening runs in different days. The frozen calls can be pooled for use in HTS that effectively minimizes the passage variations. The readily availability of frozen cells that have been stored in a freezer in aliquots allows compound screens in HTS formats without being limited by the cell culture that is usually a bottleneck in cell based screens.

In conclusion, we have developed and validated a multiplexed GPCR-calcium response assay that sequentially measures agonist activities in a rapid calcium dye assay followed by a NFAT beta-lactamase reporter gene assay. The compound activities are determined in the same cells in a single assay plate for both calcium assays, resulting in more comparable results for the same compound. It also significantly saves the screening time and cost of reagents. Therefore, this multiplex calcium assay is a useful tool for GPCR screens of large size compound libraries in the drug discovery process.

\section{CONFLICT OF INTEREST}

The authors confirm that this article content has no conflicts of interest.

\section{ACKNOWLEDGEMENTS}

The authors acknowledge C.K. Chan, Sally Daniels, Christopher Haber, Eric Nordby, Benjamin Turner, Jurgen Vanhauwe, Rathna Iyer, Donald Vanleeuwen, Kevin Wass, Scott Wise, and Jeff Scholten. 


\section{ABBREVIATIONS}

$\begin{array}{ll}\text { BLA } & =\text { beta-lactamase } \\ \text { FLIPR } & =\text { Fluorometric Imaging Plate Reader } \\ \text { GPCR } & =\text { G-protein coupled receptor } \\ \text { HTS } & =\text { high throughput screening } \\ \text { MT1 receptor } & =\text { melatonin receptor 1 } \\ \text { NFAT } & =\text { Nuclear factor of activated T-cells } \\ \text { DAG } & =\text { diacylglycerol } \\ \text { IP3 } & =\text { inositol trisphosphate }\end{array}$

\section{REFERENCES}

Flordellis CS. The plasticity of the 7TMR signaling machinery and the search for pharmacological selectivity. Curr Pharm Des 2012; 18: $145-60$.

[2] Kimple AJ, Bosch DE, Giguere PM, Siderovski DP. Regulators of G-protein signaling and their Galpha substrates: promises and challenges in their use as drug discovery targets. Pharmacol Rev 2011; 63: 728-49.
[3] Hopkins AL, Groom CR. The druggable genome. Nat Rev Drug Discov 2002; 1: 727-30.

[4] Wise A, Gearing K, Rees S. Target validation of G-protein coupled receptors. Drug Discov Today 2002; 7: 235-46.

[5] Hauptschein RS, Eustace BK, Jay DG. Global high-throughput screens for cellular function. Exp Hematol 2002; 30: 381-7.

[6] Johnston PA. Cellular platforms for HTS: three case studies. Drug Discov Today 2002; 7: 353-63.

[7] Liu K, Titus S, Southall N, et al. Comparison on functional assays for Gq-coupled GPCRs by measuring inositol monophospate-1 and intracellular calcium in 1536-well plate format. Curr Chem Genomics 2008; 1: 70-8.

[8] Oosterom J, van Doornmalen EJ, Lobregt S, Blomenrohr M, Zaman GJ. High-throughput screening using beta-lactamase reporter-gene technology for identification of low-molecularweight antagonists of the human gonadotropin releasing hormone receptor. Assay Drug Dev Technol 2005; 3: 143-54.

[9] Zlokarnik G, Negulescu PA, Knapp TE, et al. Quantitation of transcription and clonal selection of single living cells with betalactamase as reporter. Science 1998; 279: 84-8.

[10] Kunapuli P, Ransom R, Murphy KL, et al. Development of an intact cell reporter gene beta-lactamase assay for $\mathrm{G}$ protein-coupled receptors for high-throughput screening. Anal Biochem 2003; 314: $16-29$.

(C) Sheth et al.; Licensee Bentham Open.

This is an open access article licensed under the terms of the Creative Commons Attribution Non-Commercial License (http://creativecommons.org/licenses/by-nc/3.0/) which permits unrestricted, non-commercial use, distribution and reproduction in any medium, provided the work is properly cited. 